\title{
Long-delay taste aversion learning: Effects of repeated trials and two-bottle testing conditions
}

\author{
ANTHONY L. RILEY and JOHN P. MASTROPAOLO \\ The American University, Washington, DC
}

\begin{abstract}
Animals injected $1 \mathrm{~h}$ following saccharin consumption displayed a significant decrease in saccharin intake on a subsequent one-bottle exposure. Animals poisoned 5 and $10 \mathrm{~h}$ following saccharin consumption failed to decrease subsequent intake. With repeated trials or with a twobottle testing procedure, the subjects in the 5 -h delay condition displayed a significant aversion to saccharin. These data suggest that a number of nontemporal factors, in this case the number of conditioning trials and the testing procedure, affect the temporal gradient within taste-aversion learning. Under no conditions did the 10-h delay groups display an aversion to saccharin, suggesting a real limit on the delay that can be imposed between taste exposure and the administration of the toxin and on the extent of taste memory within the aversion design.
\end{abstract}

Although taste aversions can be acquired over long delays, there does appear to be some temporal constraint on the length of this delay; specifically, aversions seldom are acquired when delays exceed 8-12 h (for reviews, see Domjan, 1985; Riley \& Tuck, 1985a, 1985b). Yet although 8-12 $\mathrm{h}$ does appear to be the point beyond which animals do not learn taste aversions (see, however, Etscorn \& Stephens, 1973), within this limit the delay interval is subject to a number of manipulations. For example, increases in the concentration of the taste stimulus (Andrews \& Braveman, 1975; Braun \& Rosenthal, 1976) or in the dose of the toxin (Revusky, 1968) increase the delay over which animals can learn the aversion. Similar effects have been reported with variations in the duration of the taste exposure (Deutsch, 1978).

If the delay over which taste aversion learning can occur is subject to manipulations that affect aversion learning in general, it should be expected that other manipulations that increase the likelihood of acquiring or displaying an aversion would affect the delay length as well. This prediction was tested in the following experiments in which delay learning was assessed with repeated conditioning trials (Experiment 1) and within a two-bottle aversion test (Experiment 2), both of which procedures are relatively sensitive in the assaying of taste aversions (see Goudie, 1987; Klosterhalfen \& Klosterhalfen, 1985; Riley \& Tuck, 1985b).

The authors would like to thank Regina Bankes and Rebecca Early for technical assistance throughout the conduct of this research. This research was supported by a faculty development grant from The American University and by a Mellon Foundation grant. Requests for reprints should be sent to Anthony L. Riley, Psychopharmacology Laboratory, Department of Psychology, The American University, Washington, DC 20016. John P. Mastropaolo is currently at the Veterans Administration, Psychiatry Service (116A), VA Medical Center, 50 Irving St., Washington, DC 20422.

\section{EXPERIMENT 1}

\section{Method}

Subjects and Apparatus. The subjects were 24 experimentally naive, female rats of Long-Evans descent, approximately 90 days of age at the beginning of the experiment. They were maintained on a 12:12-h light:dark cycle for the duration of the experiment, at an ambient temperature of $23^{\circ} \mathrm{C}$. All subjects were housed in individual wire mesh cages for the duration of the experiment.

Procedure. Following water deprivation, all subjects were given a 20 -min access to water once a day for 19 consecutive days. At this point, all subjects were drinking from the tube within $2 \mathrm{sec}$ of its presentation. On Day 20, saccharin (0.1\% Sodium Saccharin, Fisher Purified) replaced water during the daily 20 -min fluid-access period. Differential treatment was then administered to four groups of subjects $(n=6$ per group). The subjects in Group 1 were given an intraperitoneal (IP) injection of $1.8 \mathrm{mEq}, 0.15 \mathrm{M} \mathrm{LiCl}(76 \mathrm{mg} / \mathrm{kg}), 1 \mathrm{~h}$ following the 20 min exposure to saccharin. The subjects in Groups 5 and 10 were injected with this same dose of $\mathrm{LiCl} 5$ and $10 \mathrm{~h}$ following saccharin access, respectively. The subjects in Group $\mathrm{C}$ were given an equivolume injection of the distilled water vehicle at 1,5 , or $10 \mathrm{~h}$ following saccharin access ( $n=2$ for each delay). On each of the following 3 waterrecovery days, all subjects were given a 20-min access to water.

On the following day (Day 24), saccharin was again substituted for water during the 20-min fluid-access period. As above, Groups 1, 5, and 10 were injected with $\mathrm{LiCl} 1,5$, and $10 \mathrm{~h}$ following this 20-min period, respectively. The subjects in Group $\mathrm{C}$ again received a control injection at their respective delays. As above, on each of the following 3 water-recovery days all subjects were given a 20 -min access to water. This cycle of conditioning/water recovery was repeated until all the subjects had received a total of five complete cycles. On the day following the last water-recovery period, all the subjects were given a 20-min access to saccharin in a final one-bottle test of the aversion to saccharin.

\section{Results}

All statistical inferences were based on an analysis of variance, and group differences were determined using the least significant difference test. All reported significant differences are at the $p<.05$ level, two-tailed.

Figure 1 illustrates saccharin consumption on each of the repeated conditioning trials. Water consumption in the water-recovery sessions following each of these trials is also presented. When saccharin replaced water on the first 


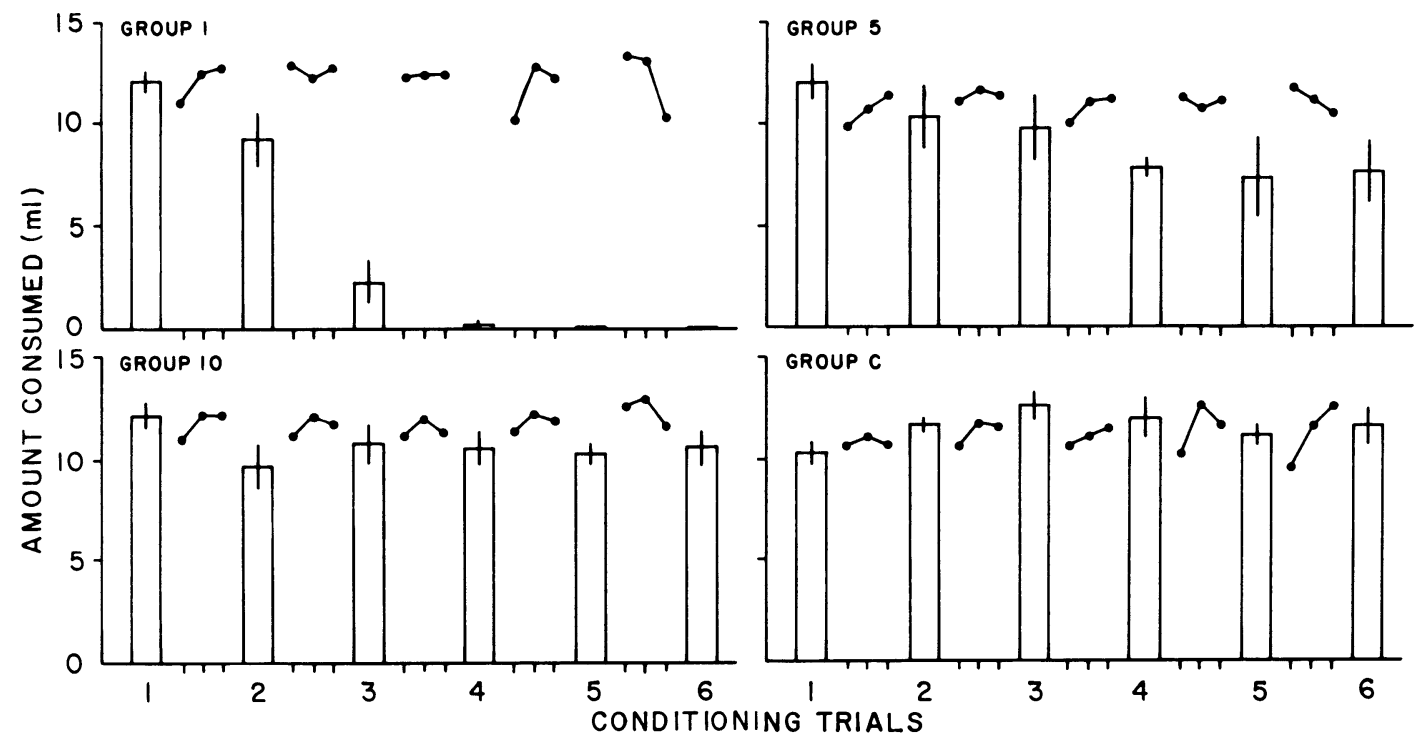

Figure 1. Amount of saccharin consumed (open bars) over repeated one-bottle conditioning trials for Groups 1, 5,10 , and $\mathrm{C}$. The $S E M$ for each trial is represented by the vertical line within the open bar. Connected dots represent amount of water consumed during water-recovery sessions between successive conditioning trials.

conditioning trial, all groups drank approximately $12 \mathrm{ml}$ (see Figure 1, Conditioning Trial 1). There were no significant differences in consumption on this exposure from the previous 3 days' water baseline for any group.

On the second conditioning trial, significant differences emerged in saccharin consumption among the four groups of subjects (see Figure 1, Conditioning Trial 2). Consumption for the subjects in Group 1 was significantly decreased relative to their consumption during the initial exposure to saccharin. The subjects in the remaining groups did not display any significant change in saccharin consumption from their prepoisoned baseline. During this exposure, Group 1 drank significantly less saccharin than the nonpoisoned controls (Group C). No other comparisons were significant for this exposure to saccharin.

With repeated conditioning trials, Group 1 continued to decrease saccharin consumption, drinking less than $0.5 \mathrm{ml}$ on the final aversion test (see Figure 1, Conditioning Trial 6). Although the subjects in Group 5 did not significantly decrease saccharin consumption on the second conditioning trial, with repeated conditioning these subjects drank significantly less saccharin relative to saccharin consumed during their initial exposure. On the final aversion test, these subjects drank approximately $7 \mathrm{ml}$ of saccharin. The subjects in Groups 10 and $C$ showed no significant changes in saccharin consumption over repeated conditioning trials, drinking approximately 12 and $13 \mathrm{ml}$ on the final aversion test, respectively. On this test, the subjects in Group 1 drank significantly less saccharin than the subjects in Groups 5,10, and C. The subjects in Group 5 drank significantly less than the nonpoisoned controls. Groups 10 and $\mathrm{C}$ did not differ in saccharin consumption during this final exposure to saccha- rin. Water consumption during water-recovery sessions did not differ from the prepoisoned water baseline for any group at any point during conditioning.

\section{EXPERIMENT 2}

\section{Method}

Subjects and Apparatus. The subjects were 24 experimentally naive rats of the same age, sex, and strain, and maintained under the same conditions, as were the rats in Experiment 1.

Procedure. The subjects in Experiment 2 were treated identically to those in Experiment 1, except that, following the first conditioning/waterrecovery cycle, these subjects were given access to both saccharin and water in a 20 -min two-bottle preference test. At 1,5 , or $10 \mathrm{~h}$ following this test, these subjects were injected with $\mathrm{LiCl}$ (or distilled water; Group C). As above, all subjects were given a 20-min access to water during the following three water-recovery sessions. This cycle of twobottle conditioning/water recovery was repeated until all the subjects had received a total of four complete cycles. On the day following the last water-recovery period, all the subjects were given a 20-min twobottle preference test between saccharin and water.

\section{Results}

When saccharin initially replaced water on the onebottle conditioning trial, all the subjects consumed approximately $13 \mathrm{ml}$ of saccharin. There were no significant differences in consumption during this exposure from the previous 3 days' water baseline for any group.

Figure 2 illustrates saccharin consumption on each of the repeated two-bottle conditioning trials (water consumption not shown). Water consumption during the water-recovery sessions following each of these trials is also presented. As illustrated, both Groups 1 and 5 drank significantly less saccharin than Groups 10 and $C$ on the initial two-bottle conditioning trial (see Figure 2, TwoBottle Trial 1). Neither Groups 1 and 5 nor Groups 10 


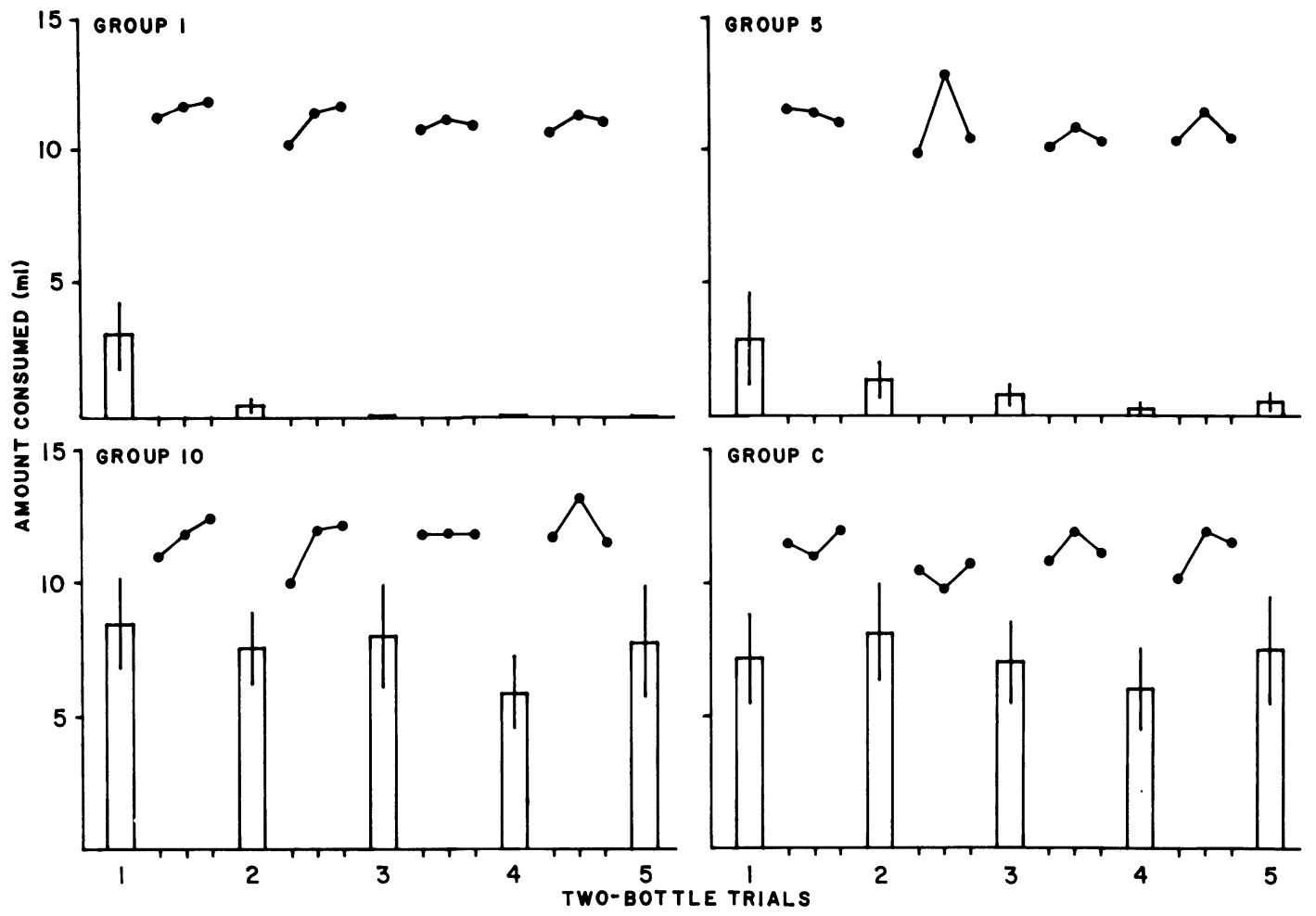

Figure 2. Amount of saccharin consumed (open bars) over repeated two-bottle conditioning trials for Groups 1, 5 , 10 , and $\mathrm{C}$. The $S E M$ for each trial is represented by the vertical line within the open bar. Water consumption on each conditioning trial is not illustrated. Connected dots represented amount of water consumed during water-recovery sessions between successive conditioning trials.

and $\mathrm{C}$ differed from each other. There were no significant differences among groups in the overall level of fluid consumption (saccharin + water) on this conditioning trial.

With repeated conditioning trials, Groups 1 and 5 further decreased consumption of saccharin, each group drinking less than $1 \mathrm{ml}$ of saccharin on the final two-bottle trial. The subjects in Groups 10 and $\mathrm{C}$ showed no significant changes in saccharin consumption over repeated conditioning trials, each group drinking approximately $8 \mathrm{ml}$ of saccharin on this trial. On the final two-bottle trial, Groups 1 and 5 drank significantly less saccharin than Groups 10 and C. Neither Groups 1 and 5 nor Groups 10 and $\mathrm{C}$ differed from each other. Overall fluid consumption (saccharin + water) did not differ among groups at any point in conditioning or on the final aversion test. Furthermore, water consumption on water-recovery sessions was never different from the preconditioning water baseline for any group at any point during conditioning.

\section{DISCUSSION}

From both Experiments 1 and 2, it is clear that the delay gradient in taste-aversion learning is affected by nontemporal parameters. Specifically, although subjects injected with $\mathrm{LiCl} 5 \mathrm{~h}$ following saccharin consumption in Experiment 1 displayed no aversion after a single conditioning trial, they did significantly decrease saccharin consumption with repeated conditioning (Experiment 1 ), and also did so after only a single conditioning trial when a two-bottle test was given (Experiment 2). Thus, conclusions regarding the temporal gradient are depen- dent upon whether one is describing the gradient after only a single trial, with repeated trials, under a one-bottle testing condition, or under a twobottle design. Similar to the work on varying taste concentration, taste duration, and toxin dose (see above), the present data demonstrate that characteristics of the delay gradient are a function of a range of factors.

It is interesting in this context that although the temporal gradient was affected by repeated conditioning trials and the use of the more sensitive two-bottle design, the previously reported limit of the delay was not affected. That is, aversions were still not evident beyond 8-12 h (in this specific research, at $10 \mathrm{~h}$ ), suggesting that there may in fact be a real limit on the delay over which animals can associate a taste and toxicosis. Although there is no consensus as to why aversions weaken with increasing delays (e.g., learned safety, interference, memory decay; see Domjan, 1985), it is possible that this limit may reflect the extent of taste memory within this design.

\section{REFERENCES}

Andrews, E. A., \& Braveman, N. S. (1975). The combined effects of dosage level and interstimulus interval on the formation of onetrial poison-based aversions in rats. Animal Learning \& Behavior, 3, 287-289.

Braun, J. J., \& Rosenthal, B. (1976). Relative salience of saccharin and quinine in long-delay taste aversion learning. Behavioral Biology, 16, 341-352.

DeUTSCH, R. (1978). Effects of CS amount on conditioned taste aversion at different CS-US intervals. Animal Learning \& Behavior, 6 , 258-260.

Domsan, M. (1985). Cue-consequence specificity and long-delay learning revisited. Annals of the New York Academy of Sciences, 443, 54-66.

ETSCORN, F., \& STEPHENS, R. (1973). Establishment of conditioned taste aversions with a 24-hour CS-US interval. Physiological Psychology, 1, 251-253.

GoudiE, A. J. (1987). Aversive stimulus properties of drugs: The conditioned taste aversion paradigm. In A. Greenshaw \& C. Dourish 
(Eds.), Experimental psychopharmacology: Concepts and methods (pp. 341-391). New Jersey: Humana Press.

Klosterhalfen, S., \& Klosterhalfen, W. (1985). Conditioned taste aversion and traditional learning. Psychological Research, 47, 71-94.

RevUSKY, S. H. (1968). Aversion to sucrose produced by contingent $\mathrm{x}$-irradiation: Temporal and dosage parameters. Journal of Comparative \& Physiological Psychology, 65, 17-22.

Riley, A. L., \& TUCK, D. L. (1985a). Conditioned food aversions:
A bibliography. Annals of the New York Academy of Sciences, 443, $381-437$.

Riley, A. L., \& TuCK, D. L. (1985b). Conditioned taste aversions: A behavioral index of toxicity. Annals of the New York Academy of Sciences, 443, 272-292.

(Manuscript received July 30, 1988.) 